\title{
A Modified Dual-Baseline PolInSAR Method for Forest Height Estimation
}

\author{
Qinghua Xie ${ }^{1,2}$, Jianjun Zhu ${ }^{1, *}$, Changcheng Wang ${ }^{1, *}$ (D), Haiqiang Fu ${ }^{1}$, \\ Juan M. Lopez-Sanchez ${ }^{2}$ (iD) and J. David Ballester-Berman ${ }^{2}$ \\ 1 School of Geosciences and Info-Physics, Central South University, Changsha 410083, China; \\ csuxqh@csu.edu.cn (Q.X.); haiqiangfu@csu.edu.cn (H.F.) \\ 2 Institute for Computing Research (IUII), University of Alicante, E-03080 Alicante, Spain; \\ juanma.lopez@ua.es (J.M.L.-S); davidb@ua.es (J.D.B.-B) \\ * Correspondence: zjj@csu.edu.cn (J.Z.); wangchangcheng@csu.edu.cn (C.W.); Tel.: +86-731-8883-6931 (C.W.) \\ Academic Editors: Irena Hajnsek, Klaus Scipal, Pascale Dubois-Fernandez, Torbjorn Eltoft, Nicolas Baghdadi \\ and Prasad S. Thenkabail \\ Received: 26 May 2017; Accepted: 4 August 2017; Published: 9 August 2017
}

\begin{abstract}
This paper investigates the potentials and limitations of a simple dual-baseline PolInSAR (DBPI) method for forest height inversion. This DBPI method follows the classical three-stage inversion method's idea used in single baseline PolInSAR (SBPI) inversion, but it avoids the assumption of the smallest ground-to-volume amplitude ratio (GVR) by employing an additional baseline to constrain the inversion procedure. In this paper, we present for the first time an assessment of such a method on real PolInSAR data over boreal forest. Additionally, we propose an improvement on the original DBPI method by incorporating the sloped random volume over ground (S-RVoG) model in order to reduce the range terrain slope effect. Therefore, a digital elevation model (DEM) is needed to provide the slope information in the proposed method. Three scenes of P-band airborne PolInSAR data acquired by E-SAR and light detection and ranging (LIDAR) data available in the BioSAR2008 campaign are employed for testing purposes. The performance of the SBPI, DBPI, and modified DBPI methods is compared. The results show that the DBPI method extracts forest heights with an average root mean square error (RMSE) of $4.72 \mathrm{~m}$ against LIDAR heights for trees of $18 \mathrm{~m}$ height on average. It presents a significant improvement of forest height accuracy over the SBPI method (with a stand-level mean improvement of $42.86 \%$ ). Concerning the modified DBPI method, it consistently improves the accuracy of forest height inversion over sloped areas. This improvement reaches a stand-level mean of $21.72 \%$ improvement (with a mean RMSE of $4.63 \mathrm{~m}$ ) for slopes greater than $10^{\circ}$.
\end{abstract}

Keywords: forest height; polarimetric SAR interferometry (PolInSAR); dual-baseline; synthetic aperture radar (SAR); sloped random volume over ground (S-RVoG) model; P-band

\section{Introduction}

Forest height is a key biophysical parameter for stand characterization, forest biomass estimation, ecosystem modeling, and logging activities detection [1,2]. In the past few decades, polarimetric synthetic aperture radar (SAR) interferometry (PolInSAR) has been demonstrated to be a promising remote sensing technique for forest height mapping on a regional or even global scale by using a physically coherent scattering model relying on PolInSAR coherence, i.e., the random volume over ground (RVoG) model [3-8]. Forest height retrieval over different forest types (e.g., boreal, tropical, temperate) based on this model has been demonstrated and validated with air- and space-borne PolInSAR data at different radar bands (e.g., X-, C-, L-, P-band) [9-19]. The experimental results indicate that the performance of model-based forest height estimation depends on a number of 
factors, such as the extinction coefficient [10,12], forest density [20], forest vertical structure [21], wind-induced temporal decorrelation [22], dielectric-induced temporal decorrelation [23], terrain slope [24], and vertical wavenumber [25]. Various research works have been carried out to account for these effects by modifying the RVoG model [21-24]. With regard to terrain slope impact modeling, Lu et al. proposed a sloped random volume over ground (S-RVoG) model by introducing a parameter of the range terrain slope inside the RVoG model [24]. The experimental results indicate that a positive slope results in an overestimation of forest height, and a negative slope introduces an underestimation of forest height [24-27]. Moreover, the S-RVoG model has been demonstrated to be helpful to improve the performance of forest height estimation by using simulated and real PolInSAR data in a single-baseline configuration [24-27]. In practice, forests are usually distributed over non-flat areas; however, previous experiments usually were implemented in relatively flat areas because the RVoG model holds the assumption of flat ground [3-8]. Therefore, from the perspective of a practical application, S-RVoG model provides us the possibility to mitigate the impact of terrain slope on forest height inversion. The validation of this model over different forest areas is currently the object of active research.

For a more reliable forest height estimation, in addition to improving the accuracy of scattering modeling, the investigation of baseline diversity is also an alternative direction. Dual- or multi-baseline PolInSAR configurations lead to a higher number of observables, and hence it potentially allows investigators to obtain more details of a forest's vertical structure [13,19,28-31], and can also compensate or filter out forest height estimation results with strong errors [31]. In previous works related to multi-baseline PolInSAR forest height inversion, the parameter inversion algorithms usually deal with a nonlinear optimization problem by using a set of complex interferometric coherences from different baselines. The inversion performance often affected by the starting values of the parameters (initial guess) and the optimization algorithm itself $[13,19]$. Moreover, the complexity of these methods is high, and numerical issues can hamper a successful retrieval as the number of baselines increases. On the contrary, the three-stage algorithm proposed by Cloude et al. [8] for a single-baseline PolInSAR configuration provides a geometrical, simple, and fast approach for forest height retrieval, whose capability has been widely demonstrated over different forest areas [9-12]. However, despite these advantages, the robustness of this method strongly depends on the assumption that the ground-to-volume amplitude ratio (GVR) in one of the observed polarization channels is small (usually less than $-10 \mathrm{~dB}$ for securing $10 \%$ forest height accuracy) [8]. Moreover, this assumption is difficult to validate for the long wavelength radar observation case with high penetrability and sparse forest area, because a strong scattering contribution from the ground is present in all polarizations. To reduce this limitation, Cloude subsequently proposed a dual-baseline PolInSAR (DBPI) method by expanding the three-stage algorithm in the dual-baseline configuration [28]. This DBPI method is also a geometrical method, but no longer needs to hold the smallest GVR assumption as in the single baseline PolInSAR (SBPI) case. However, the performance of this method by using real PolInSAR data has not been studied up to now.

In this paper, comprehensive tests over boreal forest by using real PolInSAR data are first presented to validate the DBPI method. This method was originally proposed by Cloude, and its performance was assessed by using numerical simulations. Additionally, in order to account for the range terrain slope effect on forest height estimation, a modified DBPI method is proposed in which the S-RVoG model is exploited. The structure of this paper is as follows. In Section 2, the RVoG model, the SBPI method based on the three-stage algorithm, and Cloude's DBPI method are briefly reviewed. Then, the S-RVoG model for considering the range slope effect is introduced. Next, the modified DBPI method by incorporating the S-RVoG model is proposed. Section 3 briefly introduces the test site and the PolInSAR data sets. P-band fully polarimetric E-SAR images and LIDAR forest height products from the BioSAR2008 campaign are exploited for testing purposes. In Section 4, two comparative analyses for testing different methods are performed. In first place, a comparative analysis of forest height results from both the SBPI and Cloude's DBPI methods is conducted to compare their performance. The second analysis employs external DEM data for obtaining the slope information, and then the 
modified DBPI method is tested. Afterwards, a detailed analysis of the results is conducted to show the improvements of the proposed method against Cloude's original DBPI method. Finally, discussions on the implications are made and conclusions on the work are drawn in Sections 5 and 6, respectively.

\section{Methods for Model-Based PolInSAR Forest Height Inversion}

\subsection{PolInSAR Coherence}

As is well-known, Interferometric SAR (InSAR) complex coherences in different polarization channels (i.e., PolInSAR coherence) are the basic observations in model-based PolInSAR forest height inversion methods. The interferometric coherence for two SAR images $S_{1}$ and $S_{2}$ at a given polarization is expressed as [6]

$$
\gamma(\omega)=\frac{\left\langle S_{1}(\omega) \cdot S_{2}^{*}(\omega)\right\rangle}{\sqrt{\left\langle S_{1}(\omega) \cdot S_{1}^{*}(\omega)\right\rangle\left\langle S_{2}(\omega) \cdot S_{2}^{*}(\omega)\right\rangle}}
$$

where $\omega$ represents polarimetric scattering vector for an arbitrary channel in the polarization space, \langle\rangle denotes the expected value, and $\gamma(\omega)$ depends on a set of decorrelation processes. After the system calibration and spectral band filter, the estimated interferometric coherence is mainly composed of three decorrelation processes $[12,32]$

$$
\gamma(\omega)=\gamma_{t e m p}(\omega) \cdot \gamma_{S N R}(\omega) \cdot \gamma_{V o l}(\omega)
$$

where $\gamma_{\text {temp }}$ represents the temporal decorrelation, which could be real or complex valued. It relies on the stability of the scene between two image acquisitions. $\gamma_{S N R}$ denotes the noise decorrelation on the received signal, and usually affects low backscattering areas [12]. $\gamma_{V o l}$ is the volume decorrelation resulting from the different projection of the vertical component from the target into the two acquired images [3]. Accordingly, it is related to the vertical distribution of the scatterers by using a normalized Fourier transformation [3-5]

$$
\gamma_{V o l}(\omega)=e^{j k_{z} z_{0}} \frac{\int_{0}^{h_{v}} F(z) e^{j k_{z} z} d z}{\int_{0}^{h_{v}} F(z) d z}
$$

where $z$ represents the vertical dimension and $z_{0}$ is the reference height; $F(z)$ describes the vertical reflectivity function; $h_{v}$ denotes the height of the volume (i.e., forest height); $k_{z}$ represents the effective vertical wavenumber determined by the imaging geometrical parameters (i.e., perpendicular baseline $B_{\perp}$, slant range $R$, incidence angle $\theta$ ); and $\lambda$ is the radar wavelength. For the usual monostatic acquisitions, it can be described as [3]

$$
k_{z}=\frac{4 \pi B_{\perp}}{\lambda R \sin \theta} .
$$

$\gamma_{V o l}$ contains information from the vertical structure of the target. Then, in principle, it would be possible to estimate forest biophysical parameters (e.g., forest height). The physical model will be further explained in Section 2.1.

\subsection{RVoG Model}

For forest areas, the scattering mechanism is mainly characterized by the contributions from volume scattering, surface scattering and double-bounce scattering (i.e., ground-trunk or trunk-ground) [4,5,33-36]. Therefore, $F(z)$ contains the contributions from vegetation and ground scattering. The key idea for modeling $F(z)$ consists in adopting a two-layer model of a volume with a certain thickness over a flat ground. For the monostatic mode, the vertical distribution is described by using a structure function consisting of the exponential distribution function for volume scattering and a single Dirac-delta function for ground scattering. The expression of the structure function can be written as

$$
F(z)=m_{v}(\omega) \mathrm{e}^{\frac{2 \sigma}{\cos \theta} z}+m_{g}(\omega) \delta\left(z-z_{0}\right)
$$


where $\sigma$ is the mean extinction coefficient, $\delta$ is the Dirac-delta function, and $m_{v}$ and $m_{g}$ represent the volume and ground scattering amplitudes, respectively. Substituting (5) into (3) leads to [8]

$$
\gamma_{V o l}(w)=e^{j \varphi_{0}} \frac{\gamma_{V 0}+m(w)}{1+m(w)} .
$$

Equation (6) is the well-known random volume over ground (RVoG) model. $\varphi_{0}=k_{z} z_{0}$ is the ground interferometric phase, which can be used to estimate the underlying topography [37]; $m(w)=m_{g}(w) /\left(m_{v}(w) e^{2 k_{z} h_{v} / \cos \theta}\right)$ represents the amplitude ratio of ground-to-volume scattering (GVR); and $\gamma_{V 0}$ denotes the volume-only coherence, which can be written as

$$
\gamma_{V 0}=\frac{2 \sigma\left(\mathrm{e}^{2 \sigma h_{v} / \cos \theta+i k_{z} h_{v}}-1\right)}{\left(2 \sigma+i k_{z} \cos \theta\right)\left(\mathrm{e}^{2 \sigma h_{v} / \cos \theta}-1\right)} .
$$

\subsection{SBPI Method}

For a single-baseline PolInSAR (SBPI) configuration, the RVoG model-based forest height inversion methods are mainly based on multidimensional optimization algorithms $[7,22,29]$, complex least squares adjustment methods [18,37-39], or the three-stage technique $[8,40]$. While the first two approaches do not need the smallest GVR assumption, i.e., the ground-to-volume amplitude ratio (GVR) in at least one of the observed polarization channels is small enough (GVR $<-10 \mathrm{~dB}$ [8]), the last approach offers a more straightforward inversion [25]. Besides, in the final step of three-stage SBPI method (i.e., height inversion), a well-known and commonly used alternative is to fix the extinction value to some value chosen according to empirical foundations $[10,12,25]$. The three-stage SBPI method consists of a simple geometrical representation of Equation (6) on the unit circle, and has been one of the most frequently used methods [40]. The inversion procedure of this method consists of the following steps [8]:

(1) Line Fit: According to the linear signature of the coherences predicted by the RVoG model on the unit circle, this step is performed by a line regression of the complex coherence loci at a set of possible polarization channels. The polarization channels chosen for the present work consist of typical linear and Pauli basis polarization channels (HH, HV, VV, $\mathrm{HH}+\mathrm{VV}, \mathrm{HH}-\mathrm{VV})$, and the phase diversity (PD) optimized polarization channels (PDHigh, PDLow) [41]. PDHigh and PDLow represent the channels with highest and lowest phase center, respectively.

(2) Ground Phase Estimation: This step is implemented by selecting one of the two intersection points of the fitted line with the unit circumference. The solution is determined after a consideration of the rank order of the polarimetric phase-center positions. Since the PD coherence optimization method could achieve the maximum phase separation in the complex plane, it is reasonable to assume the smallest GVR for the PDHigh channel and largest GVR for the PDLow channel. Then, a slight modification of the decision rule can be derived

$$
\left|\operatorname{Arg}\left(\gamma_{P D H i g h}\right)-\varphi_{0}\right| \geq\left|\operatorname{Arg}\left(\gamma_{P D L o w}\right)-\varphi_{0}\right| .
$$

It means that the PDLow phase center should be located closer to the ground than the PDHigh phase center. The phase of the two intersection points which fulfills the Equation (8) will be chosen as the ground phase.

(3) Height Inversion: After determining the ground phase $\varphi_{0}$ and assuming $\gamma_{P D H i g h}$ is the corresponding volume-only coherence (i.e., GVR is very low), forest height and the extinction could be estimated by a two-dimensional (2D) lookup table. The criterion can be written as

$$
\min _{h_{v}, \sigma}\left|\gamma_{P D H i g h}-e^{j \varphi_{0}} \gamma_{V_{0}}\left(h_{v}, \sigma, k_{z}\right)\right| .
$$




\subsection{S-RVoG Model}

As the basic idea of the RVoG modeling, the ground is assumed to be a flat surface. However, the natural surface in forest areas often presents sloped terrain, and it will affect the forest parameter inversion $[24,42,43]$. Therefore, a more accurate RVoG model-based parameter inversion needs to investigate how to reduce the slope effect. With regard to this issue, Lu et al. proposed a sloped random volume over ground (S-RVoG) model to correct the terrain distortion efficiently [24]. The process of derivation of the S-RVoG model is intuitively implemented from the RVoG model by aligning the reference frame along the terrain slope. As shown in Figure 1, the height direction in the RVoG model is $z$ and the ground surface is the horizontal plane, whereas the height direction for the S-RVOG model is $z^{\prime}$ and the ground surface is the slope plane. In this new geometric reference frame, the incidence angle and the effective vertical wavenumber need to be slightly changed, which can be rewritten as

$$
\theta^{\prime}=\theta-\alpha ; k_{z}^{\prime}=\frac{4 \pi B_{\perp}}{\lambda R \sin \theta^{\prime}}
$$

where $\alpha$ represents the range terrain slope, which could be a positive or negative value. The terrain slopes titled towards the radar sensor are positive (see Figure 1a), whereas the slopes titled away from the radar sensor are negative (see Figure 1b). From Equation (10), it is clear that the positive slopes decrease the local incidence angle and increase the vertical wavenumber, whereas the negative slopes have the opposite effect. The corresponding vertical structure function should be expressed along $z^{\prime}$, which is given as

$$
F\left(z^{\prime}\right)=m_{v}^{\prime}(\omega) \mathrm{e}^{\frac{2 \sigma}{\cos \theta} z^{\prime}}+m_{g}^{\prime}(\omega) \delta\left(z^{\prime}-z_{0}^{\prime}\right) .
$$

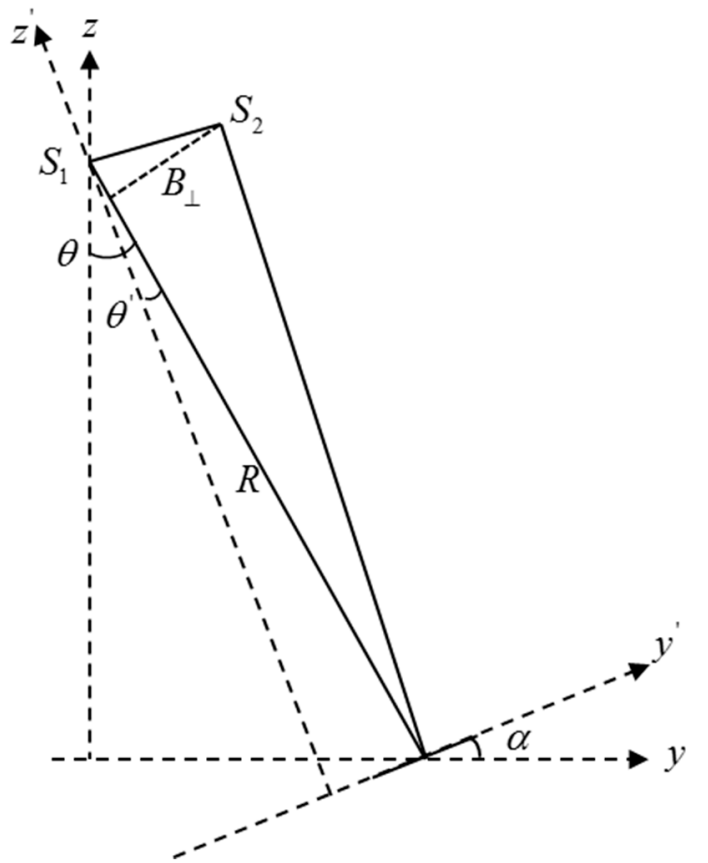

(a)

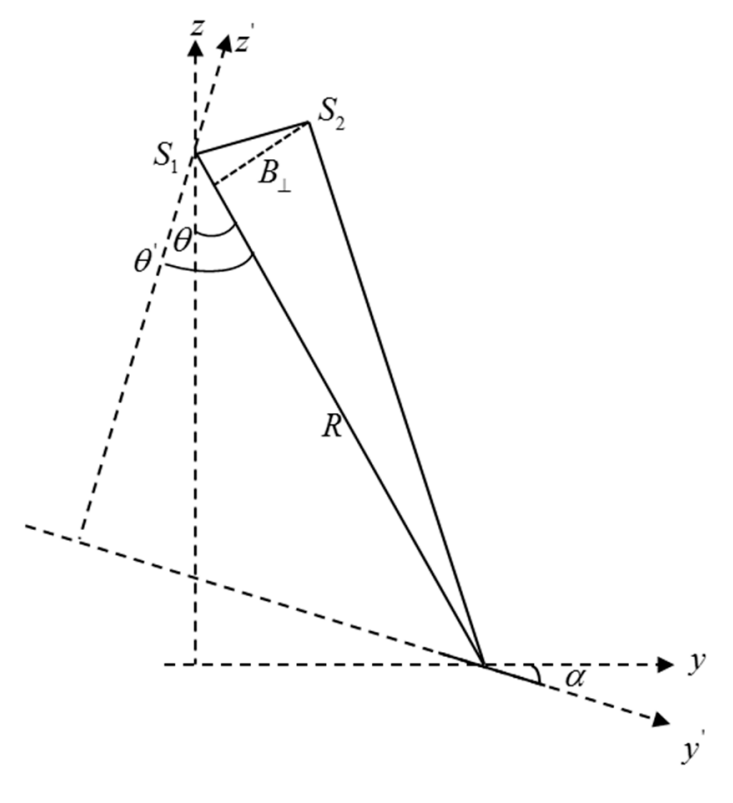

(b)

Figure 1. Geometrical reference frame for the sloped random volume over ground (S-RVoG) model. (a) Positive terrain slope; (b) Negative terrain slope. $B_{\perp}$ is the perpendicular baseline, $\theta$ is the incidence angle, $R$ is the slant range, $\alpha$ is the range terrain slope, and $\theta^{\prime}$ is the incidence angle in the new geometric reference frame. 
Then, the volume coherence can be expressed as

$$
\gamma_{V o l}^{\prime}=e^{j \varphi_{0}} \frac{\int_{0}^{h_{v} \cos \alpha} F\left(z^{\prime}\right) e^{j k_{z}^{\prime} z^{\prime}} d z^{\prime}}{\int_{0}^{h_{v} \cos \alpha} F\left(z^{\prime}\right) d z^{\prime}}=e^{j \varphi_{0}} \frac{\gamma_{V 0}^{\prime}+m^{\prime}(w)}{1+m^{\prime}(w)} .
$$

Equation (12) is the so-called S-RVoG model. Compared with the RVoG model, the formulation of the GVR for the S-RVoG geometry is $m^{\prime}(w)=m_{g}^{\prime}(w) /\left(m_{v}^{\prime}(w) e^{2 k_{z}^{\prime} h_{v} / \cos \theta^{\prime}}\right)$, and the corresponding volume-only coherence $\gamma_{V 0}^{\prime}$ can be written as

$$
\gamma_{V 0}^{\prime}=\frac{2 \sigma\left(\mathrm{e}^{\left(2 \sigma h_{v} / \cos \theta^{\prime}+i k_{z}^{\prime} h_{v}\right) \cos \alpha}-1\right)}{\left(2 \sigma+i k_{z}^{\prime} \cos \theta\right)\left(\mathrm{e}^{2 \sigma h_{v} \cos \alpha / \cos \theta}-1\right)} .
$$

From the expressions of the S-RVoG and RVoG models, it is intuitive to see that both models are consistent. When the slope is zero, the S-RVoG model is equal to the RVoG model. Note that the 2D look-up table for height estimation should be computed according to the volume-only coherence in the S-RVoG model (i.e., Equation (13)) [24,26].

\subsection{Cloude's DBPI Method}

In the SBPI method described above, the robustness of the inversion procedure depends on the assumption that the GVR ratio in at least one of the observed polarization channels is small (usually less than $-10 \mathrm{~dB}$ for securing $10 \%$ forest height accuracy) [8]. With regard to this limitation, Cloude proposed a simple but reliable inversion method without the assumption about the minimum GVR, which is based on a dual-baseline PolInSAR (DBPI) configuration [28]. In this method, the volume-only coherence can be estimated after adding a second baseline. The criterion for estimation is to minimize the difference between the pure volume coherence point predicted from the first baseline and the second fitting line. The detailed procedure of this DBPI method consists of several steps, as follows:

(1) Line Fit: For the two interferometric baselines $B_{1}$ and $B_{2}$, perform separately the line fit procedure using the complex interferometric coherences associated with the same polarization channels.

(2) Ground Phase Estimation: estimate separately the ground phases $\varphi_{0}^{1}$ and $\varphi_{0}^{2}$ for both interferometric pairs according to the criterion explained above.

(3) Initial Height Inversion: For the first baseline $B_{1}$, initialize the possible candidates for volume-only coherence points by stepping along the fitted line from the initially assumed volume-only coherence point (e.g., $\gamma_{P D H i g h}$ ) to the non-ground intersection point (i.e., the excluded point at the far end of the coherence line with phase $\varphi_{e}^{1}$ ). Then, as in the height inversion in the SBPI procedure, calculate the corresponding solution pairs of forest height $h_{v}$ and extinction coefficient $\sigma$. The corresponding criterion can be expressed as

$$
\min _{h_{v}, \sigma}\left|\gamma_{P D H i g h}+\lambda\left(e^{j \varphi_{e}^{1}}-\gamma_{P D H i g h}\right)-e^{j \varphi_{0}^{1}} \gamma_{V 0}\left(h_{v}, \sigma, k_{z}\left(B_{1}\right), \theta\right)\right|, 0 \leq \lambda \leq 1 .
$$

(4) Second Height Inversion: According to the volume-only coherence model (see Equation (7)) and the vertical wavenumber of the second baseline $B_{2}$, compute the corresponding volume-only coherence set by using all solution pairs of $h_{v}, \sigma$ from the previous step. Then, with a phase shift of $\exp \left(j \varphi_{0}^{2}\right)$, the predicted volume-only coherence loci $\gamma_{\text {predicted }}$ can be derived:

$$
\gamma_{\text {predicted }}=e^{j \varphi_{0}^{2}} \gamma_{V 0}\left(h_{v}, \sigma, k_{z}\left(B_{2}\right), \theta\right) .
$$

Then, all the predicted points are plotted in the unit complex plane. The right volume-only coherence estimation should be the one which lies on the second line or provides the minimum perpendicular distance to it. The solution pairs of $h_{v}, \sigma$ associated with the right volume-only coherence 
are the final results. Assuming the second line is represented as $y=M x+C$, the corresponding rule can be expressed as

$$
\min _{h_{v}, \sigma} \frac{1}{1+M^{2}}\left|\operatorname{Im}\left(\gamma_{\text {predicted }}\right)-C-M \operatorname{Re}\left(\gamma_{\text {predicted }}\right)\right| \text {. }
$$

\subsection{Modified DBPI Method}

As explained above, Cloude's DBPI method is based on the classical RVoG model. However, this model does not consider the slope effect and hence may distort the forest parameters' estimation. With regard to this issue, the S-RVoG model was proposed to eliminate this limitation in the RVoG model, and was intuitive and successfully applied for modifying the SBPI method [24,26]. Accordingly, in order to improve the accuracy of the forest parameters inversion, we propose a modified DBPI method by employing the S-RVoG model to replace the RVoG model. Then, the procedure for the forest parameters inversion should be modified accordingly. The procedure of the modified DBPI method also consists of four steps, which can be described as follows:

(1) Line Fitting procedure as proposed in Cloude's DBPI method.

(2) Ground Phase Estimation as proposed in Cloude's DBPI method.

(3) Initial Height Inversion: Again, a 2D look-up table is generated as in Cloude's approach, but in this case it is calculated according to the model with the modified values of vertical wavenumber $k_{z}^{\prime}$ and incidence angle $\theta^{\prime}$ (see Equation (13)). The corresponding criterion can be expressed as

$$
\min _{h_{v}, \sigma}\left|\gamma_{P D H i g h}+\lambda\left(e^{j \varphi_{e}^{1}}-\gamma_{P D H i g h}\right)-e^{j \varphi_{0}^{1}} \gamma_{V 0}^{\prime}\left(h_{v}, \sigma, k_{z}^{\prime}\left(B_{1}\right), \theta^{\prime}\right)\right|, 0 \leq \lambda \leq 1 .
$$

(4) Second Height Inversion: The main process is as in Cloude's DBPI method. The difference relies in calculating the predicted volume-only coherences $\gamma_{\text {predicted }}^{\prime}$ for the second baseline (see Equation (13)). It can be expressed as

$$
\gamma_{\text {predicted }}^{\prime}=e^{j \varphi_{0}^{2}} \gamma_{V 0}^{\prime}\left(h_{v}, \sigma, k_{z}^{\prime}\left(B_{2}\right), \theta^{\prime}\right) .
$$

The according criterion for the final solution is given as

$$
\min _{h_{v}, \sigma} \frac{1}{1+M^{2}}\left|\operatorname{Im}\left(\gamma_{\text {predicted }}^{\prime}\right)-C-M \operatorname{Re}\left(\gamma_{\text {predicted }}^{\prime}\right)\right| .
$$

\section{Test Site and PolInSAR Data Set Description}

The test site selected for validation is the Krycklan catchment $\left(64^{\circ} 14^{\prime} \mathrm{N}, 19^{\circ} 46^{\prime} \mathrm{E}\right)$, located in northern Sweden. It is a typical boreal forest area, and one part of the forest is managed by the Swedish University of Agriculture Sciences. Coniferous trees (Scots pine and Norway spruce) and fractions of birch are the dominant vegetation [44]. The average value for forest height is about $18 \mathrm{~m}$, and the measured maximum value is $30 \mathrm{~m}$ [25]. The site is a hilly region with moderate slopes. The topography variation ranges from $150 \mathrm{~m}$ to $380 \mathrm{~m}$ above the mean sea level (AMSL). Three scenes of airborne P-band PolInSAR data over the test site acquired by the German Aerospace Center (DLR)'s E-SAR sensor during the BioSAR2008 campaign were collected. Two interferometric pairs (i.e., image 1-2 and image 1-3) are computed. The detailed information on the interferometer configuration is summarized in Table 1 . The $\mathrm{Kz}$ interval is relatively large because of the special geometry of the airborne measurements. The range of incidence angle is highly varying, from about $25^{\circ}$ to $60^{\circ}$. Some researchers suggest setting an interval of $\mathrm{Kz}$ to mask out too high and too low values [12]. For instance, in our case there are values of $\mathrm{Kz}$ down to 0.024 , which is very small to provide sensitivity to invert forest height. However, these extremely small values are located mostly within a small region at far-range. Therefore, we decided to show the results for the whole region, without any mask. The LIDAR forest height product was generated from collected Airborne LIDAR measurements. The external DEM with a $1 \mathrm{~m}$ grid over the test site was used to generate terrain slope information as an input to the S-RVoG model. 
Table 1. Description of airborne PolInSAR data.

\begin{tabular}{cccc}
\hline Image & Temporal Baseline (min) & Baseline $(\mathbf{m})$ & Kz Interval \\
\hline 1 & 0 & 0 & master \\
2 & 53 & 24 & $0.024-0.135$ \\
3 & 70 & 32 & $0.051-0.181$ \\
\hline
\end{tabular}

\section{Results and Analysis}

After a series of PolInSAR preprocessing steps, including image coregistration, range spectral filtering, interferometry, flat-earth removal, and multilooking, complex coherences in seven polarization channels $(\mathrm{HH}, \mathrm{HV}, \mathrm{VV}, \mathrm{HH}+\mathrm{VV}, \mathrm{HH}-\mathrm{VV}$, PDHigh, and PDLow) for two interferometric pairs (i.e., image 1-2 and image 1-3) were estimated. In the multilooking step, two azimuth looks were employed for reducing speckle noise. Then, a window size of $11 \times 11$ was used to estimate coherences. Then, the forest height was retrieved according to the different inversion methods. The detailed comparison and analysis of the results are presented next.

\subsection{SBPI vs. Cloude's DBPI}

Firstly, the SBPI method was applied to two cases of single-baseline interferometric configuration (i.e., image 1-2 and image 1-3). Then, Cloude's DBPI method was implemented. In this case, note that two cases (i.e., image 1-2 as the first baseline $B_{1}$ or image 1-3 as the first baseline $B_{1}$ ) were constructed to investigate the effect of the choice of the first baseline $B_{1}$ on the forest height estimation. Therefore, four different cases of inversion configurations were designed to retrieve the forest height. The results are shown in Figure 2. It can be seen from this figure that all of the maps present a similar spatial trend, but the two cases of DBPI configurations show overall higher estimated values (i.e., darker color) than the two cases of SBPI configurations. The LIDAR forest height map exploited for validation has been geocoded in the multilook SAR image geometry $(6472 \times 1501$ pixels for azimuth $\times$ range $)$. For cross-validation, we used a window approach to uniformly select forest stands from the whole LIDAR forest height map. First, a uniform grid with separation $30 \times 15$ pixels (azimuth $\times$ range) was applied to select the initial centre pixels of forest stands. Then, we used an average window with a size of $51 \times 51$ (i.e., 2601 pixels) for every centre pixel to select surrounding pixels. Afterwards, we removed forest stands with null height values (i.e., with non-forest pixels). Finally, a total of 362 forest stands were selected. In every selected stand, all pixels can be considered to be covered by forest. The corresponding average values of forest height for every stand were computed for validation. Certainly, other methods to select the forest stands are also feasible. For instance, some researchers manually plot the forest stand boundary after considering that, within each stand, the tree height is nearly uniform $[25,44]$. Figure 3 presents the corresponding cross-validation plots for all four cases. The Root Mean Square Error (RMSE) and the correlation coefficient $R^{2}$ were chosen for the statistical analysis of the inversion's performance. The colour of each dot represents the mean range terrain slope of the corresponding stand, scaled from $-15^{\circ}$ to $15^{\circ}$. From Figure $3 a, b$, it can be seen that the SBPI results from baseline 1-2 and baseline 1-3 are similar, with a high RMSE of $7.88 \mathrm{~m}$ and $8.63 \mathrm{~m}$, respectively. The reason for such a high bias is the significant ground scattering contribution in all polarization channels at the P-band. The assumed volume-only polarization channel (e.g., PDHigh) is not a reasonable assumption with this configuration. However, Figure $3 c, d$ shows that the DBPI results present significant improvements, with RMSEs of $4.65 \mathrm{~m}$ and $4.79 \mathrm{~m}$, respectively. The average accuracy of the DBPI results has been improved by a mean value of $42.86 \%$. The reason is explained as follows. As seen in Figure 4, in the two SBPI cases, the point corresponding to $\gamma_{P D H i g h}$ coherence is chosen as the volume-only coherence, indicated by the red hexagrams. However, in the DBPI cases, the estimated volume-only coherences are the dark crosses for the second baseline and the blue crosses for the first baseline marked inside the red circles. It is obvious that after the constraint of an additional baseline, the positions of the volume-only coherence in the DBPI cases are further than the $\gamma_{P D H i g h}$ 
point chosen in SBPI cases, and hence improve the final estimated results of forest height. It indicates that the DBPI method can compensate for the GVR estimation bias with respect to the SBPI method. As a result, it can estimate more accurately pure volume-only coherence, which is critical for forest height inversion.
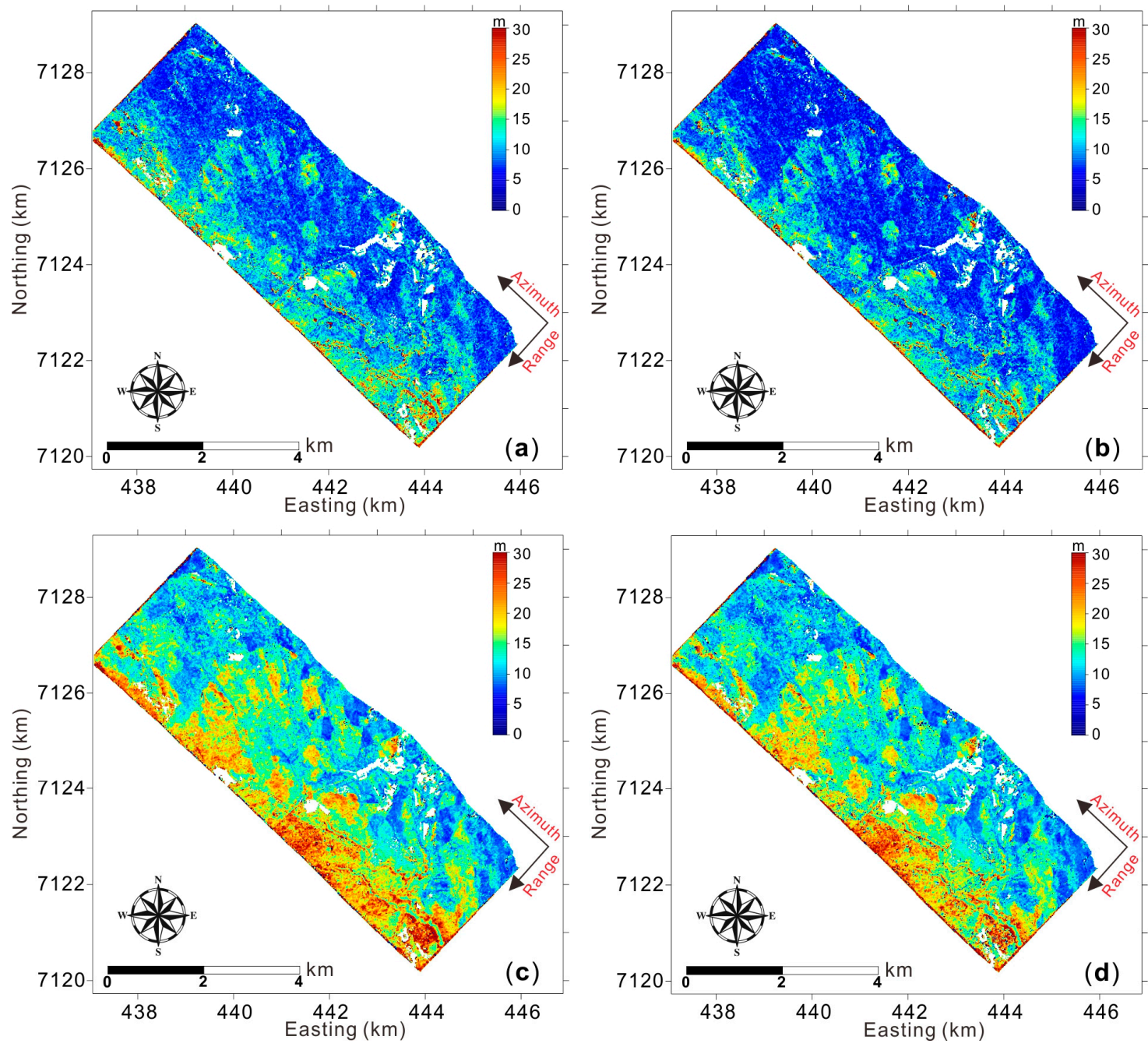

Figure 2. Forest height inversion results from four cases of inversion configurations. (a) Image 1-2 with single baseline PolInSAR (SBPI); (b) Image 1-3 with SBPI; (c) Image 1-2 as the first baseline $B_{1}$ with dual-baseline PolInSAR (DBPI); (d) Image 1-3 as the first baseline $B_{1}$ with DBPI. 

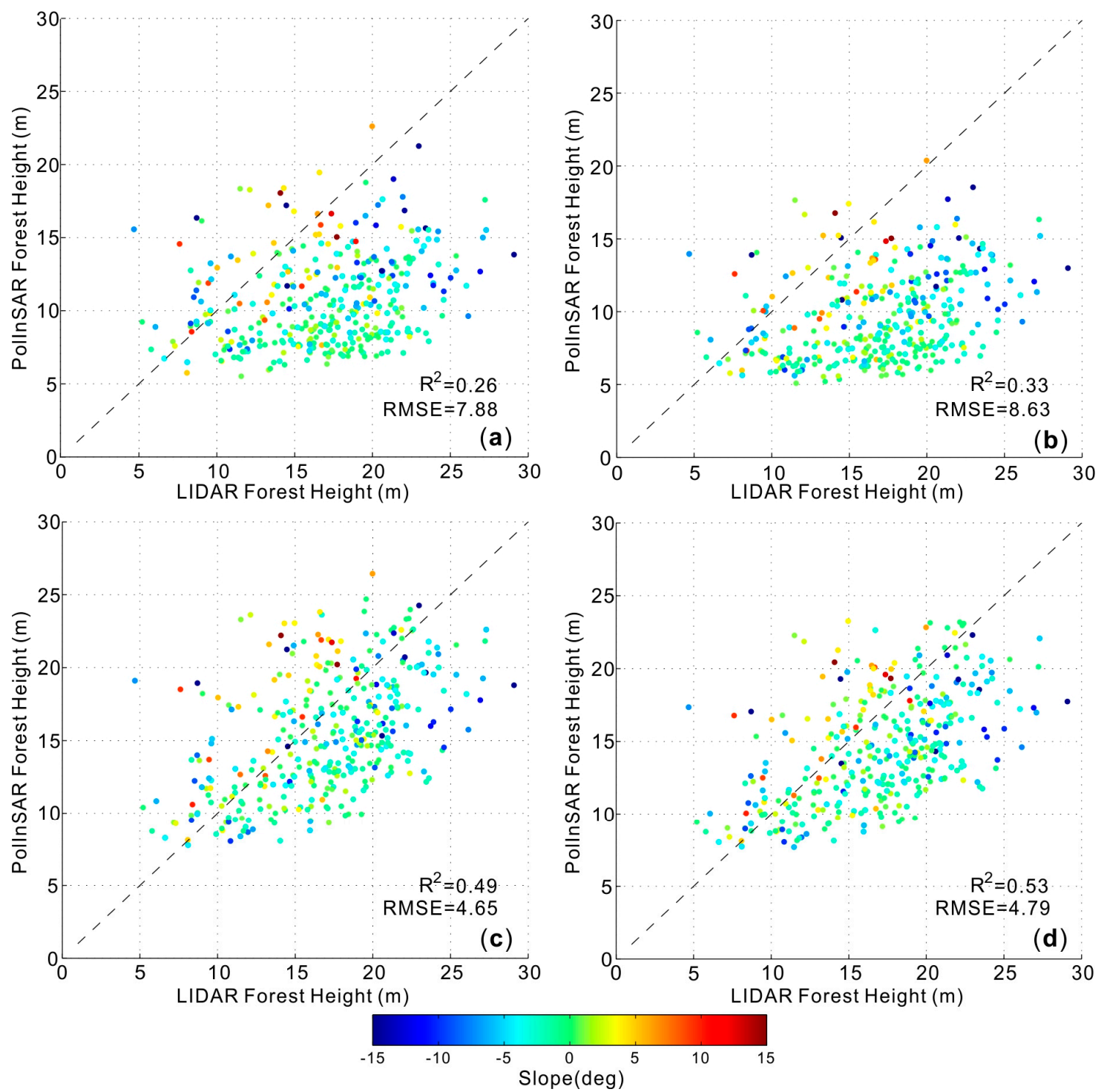

Figure 3. Validation plots of inversion results from four cases of inversion configurations; PolInSAR forest height estimates versus LIDAR forest height. (a) Image 1-2 with SBPI; (b) Image 1-3 with SBPI; (c) Image 1-2 as the first baseline $B_{1}$ with DBPI; (d) Image 1-3 as the first baseline $B_{1}$ with DBPI. The color of the stand dots represents the range terrain slope, scaled from $-15^{\circ}$ to $15^{\circ}$. RMSE, root mean square error. 

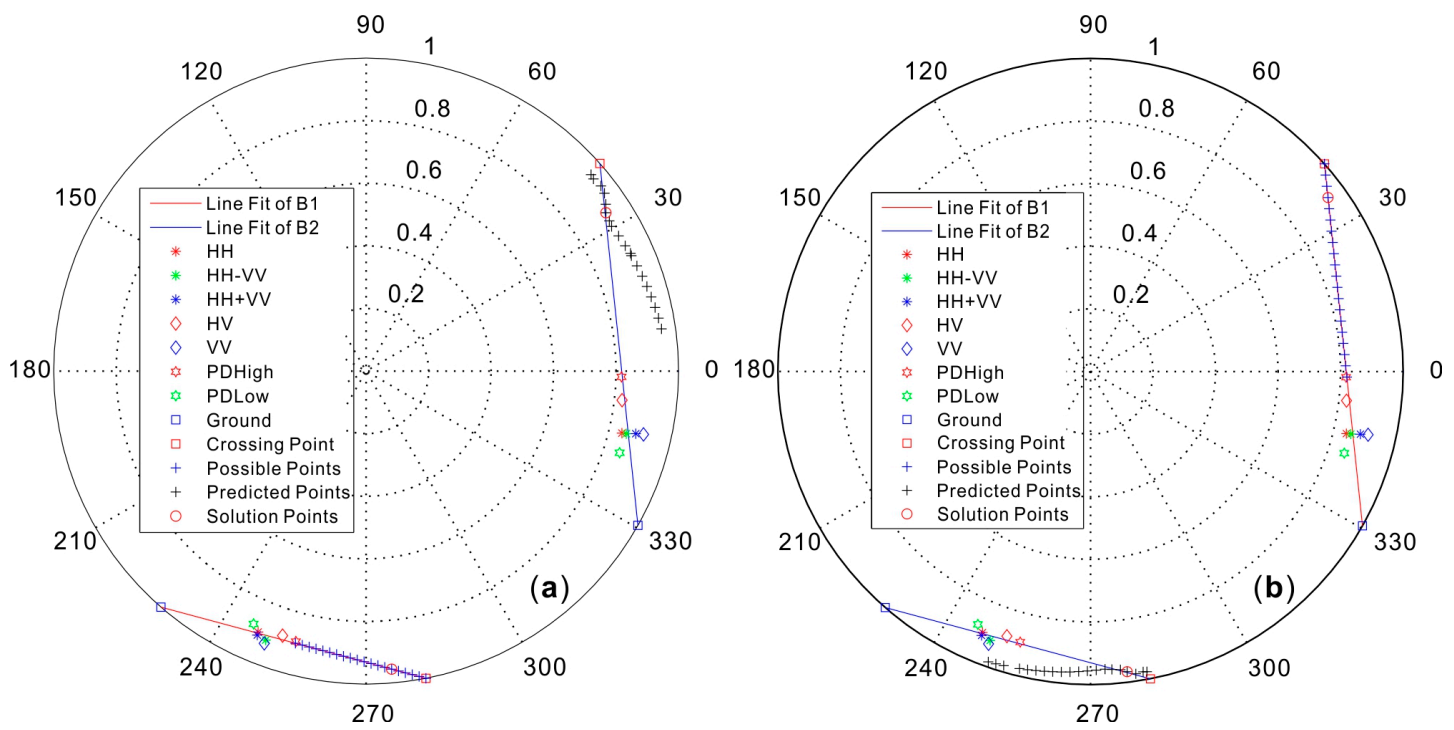

Figure 4. One example of inversion scenario for the SBPI and DBPI methods in the unit complex plane.

(a) Image 1-2 as the first baseline $B_{1}$ with DBPI; (b) Image 1-3 as the first baseline $B_{1}$ with DBPI.

\subsection{Cloude's DBPI vs. Modified DBPI}

In this section, the performance of forest height inversion based on the modified DBPI method is presented, and the results from the DBPI method are reused for a comparative analysis. Figure $5 \mathrm{a}, \mathrm{b}$ shows the forest height inversion results from the modified DBPI method with swapped choices of the first baseline. Both figures present similar trends and partial differences with respect to the results from the DBPI method (see Figure $2 c, d$ )). The estimated height difference is calculated by subtracting the DBPI results from the modified DBPI results, scaled between $-5 \mathrm{~m}$ and $5 \mathrm{~m}$, as shown in Figure $5 \mathrm{c}, \mathrm{d}$. From these figures, it is obvious that significant differences in some specific locations are detected. Figure 5e presents the range terrain slope over the test site calculated from the LIDAR DEM. As expected, the height difference maps present high correlation with the slope map. When the slope is positive, the results from the modified DBPI method decrease the height estimates with respect to the results from the DBPI method. That is because positive slopes yield an overestimation of forest height, and the S-RVoG model is able to compensate for slope effects. Conversely, negative slopes lead to an underestimation of estimates. Figure 6 presents the corresponding cross-validation plots of PolInSAR forest height estimates against the LIDAR forest height. Figure $6 \mathrm{a}, \mathrm{b}$ shows that the modified DBPI results present slight improvements, with a RMSE decrease of $7.10 \%$ on average. It must be noted that this small improvement is explained because the slopes of all of the forest stands are not large, with a mean value of $3.54^{\circ}$. In order to better understand the effect of the slope correction, 23 forest stands with relatively large range terrain slopes $\left(|\alpha|>10^{\circ}\right)$ are selected from all 362 stands, and both the original and modified DBPI methods are applied. The results included in Figure $6 c-f$ shows that the accuracy of modified DBPI method has a mean improvement of $21.72 \%$ when considering the slope correction. It indicates that when the range terrain slopes are larger than $10^{\circ}$, the bias of forest height estimation caused by the slopes needs to be considered and compensated for. However, compared with the effect of the fulfilment of the smallest GVR assumption, the terrain slope effect is of secondary importance for forest height inversion in our case. 

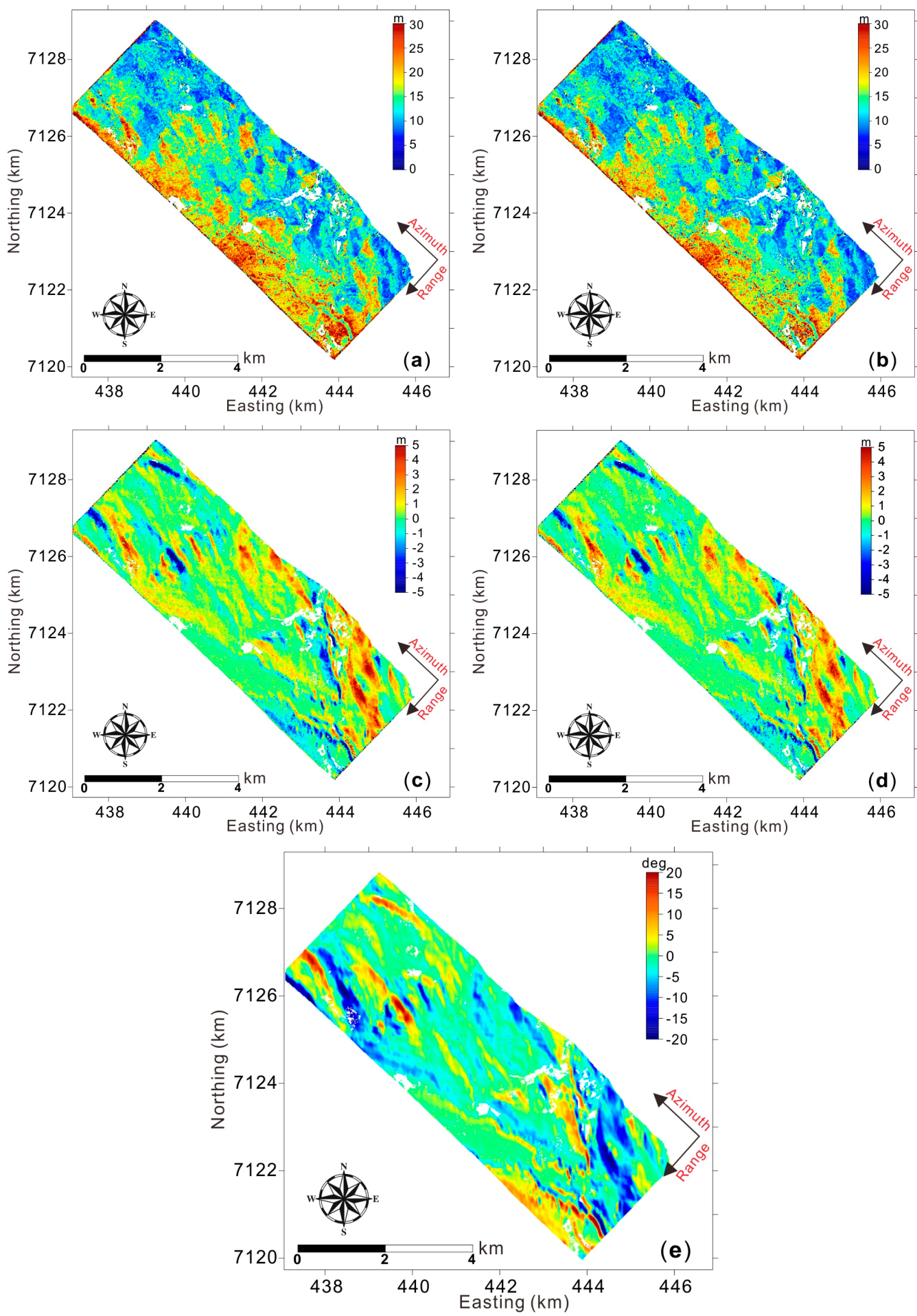

Figure 5. Forest height inversion results from the modified DBPI method. (a) Image 1-2 as the first baseline with modified DBPI; (b) Image 1-3 as the first baseline with modified DBPI. (c) Difference values of forest height between the modified DBPI and DBPI results with image 1-2 as the first baseline, scaled from $-5 \mathrm{~m}$ to $5 \mathrm{~m}$; (d) Difference values of forest height between the modified DBPI and DBPI results with image 1-3 as the first baseline, scaled from $-5 \mathrm{~m}$ to $5 \mathrm{~m}$; (e) The range terrain slope map, scaled from $-20^{\circ}$ to $20^{\circ}$. 

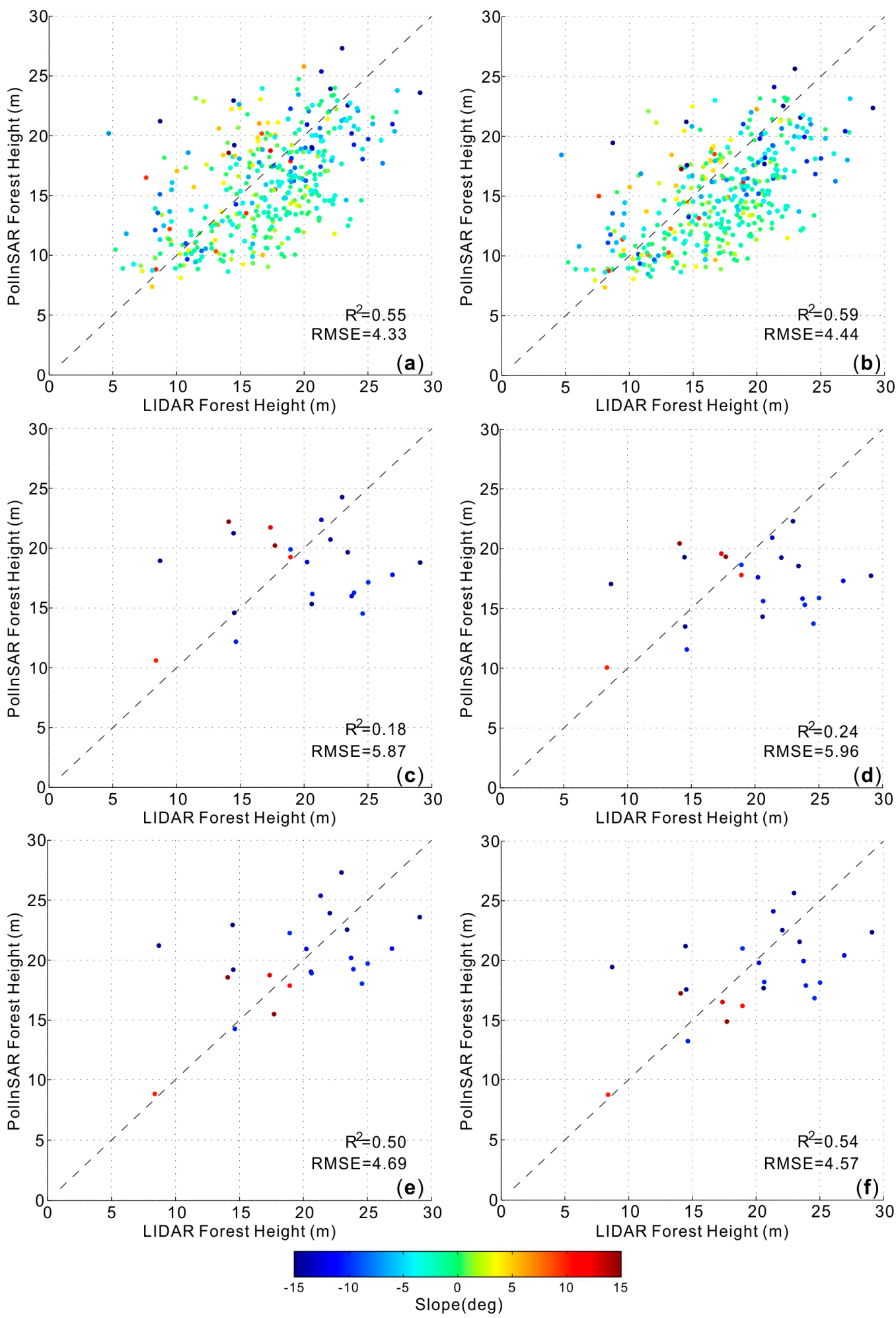

Figure 6. Validation plots of the inversion results from different inversion configurations; PolInSAR forest height estimates versus LIDAR forest height. (a) Image 1-2 as the first baseline $B_{1}$ with modified DBPI; (b) Image 1-3 as the first baseline $B_{1}$ with modified DBPI. (c) Image 1-2 as the first baseline $B_{1}$ with DBPI (slope $|\alpha|>10^{\circ}$ ); (d) Image $1-3$ as the first baseline $B_{1}$ with DBPI (slope $|\alpha|>10^{\circ}$ ). (e) Image 1-2 as the first baseline $B_{1}$ with modified DBPI (slope $|\alpha|>10^{\circ}$ ); (f) Image 1-3 as the first baseline $B_{1}$ with modified DBPI (slope $|\alpha|>10^{\circ}$ ). The color of the stand dots represents the range terrain slope, scaled from $-15^{\circ}$ to $15^{\circ}$. 


\section{Discussion}

Section 2 reviewed Cloude's dual-baseline PolInSAR forest height inversion method, and introduced a modified DBPI method by incorporating the S-RVoG model to account for the range terrain slope effect. Compared with other multi-baseline methods, such as the common multidimensional optimization method, this kind of DBPI method makes use of the geometrical signatures of PolInSAR coherences, and achieves a more intuitive and controlled forest height retrieval. The results shown in Section 4 have proven that this kind of DBPI method could significantly improve forest height results with respect to the SBPI method. In addition, the modified DBPI method is able to correct the range terrain slope impact on the forest height so that it provides the possibility to invert forest height over mountainous areas up to some extent, even though investigating the maximum allowable slope falls outside the scope of this study. Therefore, they present promising potential as simple and alternative methods for the fast mapping of forest height with large coverage and acceptable accuracy when two baselines of PolInSAR data are available. Moreover, they provide the possibility to invert forest height over mountain areas because they adopt terrain correction. Note that the modified DBPI method needs a DEM to generate the slope information, therefore the quality of the used DEM will affect the terrain correction of the forest height inversion. For instance, the Tandem-X DEM has been proved to be sufficient to correct the terrain impact on forest height inversion [25], and it is a global elevation model. Therefore, the requirement of a DEM will not limit the application of the modified DBPI method.

Some limitations of these methods are also highlighted. The line fit step could introduce errors due to the potential presence of outliers, which would modify both the orientation of the line and the length of visible line segment. It could not only affect the ground phase estimation and the possible volume-only coherence solutions in the first baseline, but also the final solution retrieved by comparing the distance between the predicted volume-only coherences and the line for the second baseline. Additionally, the assumptions of the random volume (RV) and exponential distribution structure function are not valid in some cases. It is because usually the exponential profile is fulfilled at higher frequencies, whereas a Gaussian or even linear function will characterize better the volume scattering at lower frequencies $[21,25,45]$. Moreover, the RV assumption is not valid when the crown structure presents dominant orientations. With regard to those limitations, the future work could be mainly focused on some possible directions. One is to use a more robust line fitting method to improve the accuracy, such as the coherence region method [46] and the Maximum Likelihood method that exploits the whole of the matrix statistics [47]. Both methods employ the complete polarimetric and interferometric information. The first method is designed to reconstruct the boundary of the coherence region and find the two points on the boundary with the maximum distance. The latter method exploits the whole of the matrix information to estimate the line parameters in an analytical way. Another future line consists in developing other modified DBPI methods to fit oriented vegetation structures and other scattering distribution functions. For instance, develop the DBPI method to estimate vegetation height in agriculture areas where crops usually have an oriented structure [48,49]. In addition, expanding the DBPI methods to the compact polarization configuration is also worth investigation. Besides these, incorporating the strategy with an a priori known value of extinction $[10,12,25]$ into the DBPI methods is also worth testing.

\section{Conclusions}

In this paper, we investigate forest height retrieval by using dual-baseline PolInSAR forest height inversion methods. They utilize additional baseline information to avoid the assumption of smallest GVR in the SBPI forest height inversion. Moreover, they follow the idea of using geometrical signatures of PolInSAR coherences, and hence the inversion is simple, intuitive, and controlled. Comprehensive tests over boreal forest by using real PolInSAR data are presented in this study. Additionally, in order to account for the range terrain slope effect, a modified DBPI method by incorporating the S-RVoG model is proposed. For validating the inversion methods, three scenes of P-band airborne PolInSAR 
data acquired by E-SAR and LIDAR data during the BioSAR2008 campaign are exploited to carry out two experiments of forest height retrieval. The first experiment was focused on testing and comparing the performance of the DBPI and SBPI methods. The results show that the DBPI method extracts forest heights with a mean RMSE of $4.72 \mathrm{~m}$ against LIDAR heights for trees of mean $18 \mathrm{~m}$ height. It presents a significant improvement of forest height inversion over the SBPI method (with a mean $42.86 \%$ improvement). The second experiment was designed to test the efficiency of the modified DBPI method on reducing the range terrain slope effect when an external DEM is available. The results show that the modified DBPI method reduces the range terrain slope effect, and hence improves the forest height inversion (with a mean RMSE of $4.63 \mathrm{~m}$ and a mean 21.72\% improvement at slopes higher than $10^{\circ}$ ). From these two experiments, we conclude that this kind of DBPI method offers clear potential for mountainous forest height mapping.

Acknowledgments: This work was supported in part by National Nature Science Foundation of China under Grant 41531068, 41371335, 41671356, and 41274010, the Spanish Ministry of Economy and Competitiveness and EU FEDER under Project TIN2014-55413-C2-2-P, China Scholarship Council under Grant 201406370079, and Hunan Provincial Department of Education Science Research Key Project 15A074. The BioSAR2008 campaign data is provided by European Space Agency under the ESA EO Project 14751.

Author Contributions: Qinghua Xie contributed to the design and implementation of the proposed methodology, and wrote and revised the paper; Jianjun Zhu and Changcheng Wang contributed to the discussion of the results and revised the paper; Haiqiang Fu discussed the results and drew some of the figures. Juan M. Lopez-Sanchez and J. David Ballester-Berman contributed some ideas and revised the paper.

Conflicts of Interest: The authors declare no conflict of interest.

\section{References}

1. Pan, Y.; Birdsey, R.A.; Fang, J.; Houghton, R.; Kauppi, P.E.; Kurz, W.A.; Phillips, O.L.; Shvidenko, A.; Lewis, S.L.; Canadell, J.G.; et al. A Large and Persistent Carbon Sink in the World's Forests. Science 2011, 333, 988-993. [CrossRef] [PubMed]

2. Houghton, R.A.; Hall, F.; Goetz, S.J. Importance of biomass in the global carbon cycle. J. Geophys. Res. Biogeosci. 2009, 114, 1-13. [CrossRef]

3. Cloude, S.R. Polarisation: Applications in Remote Sensing; Oxford University Press: New York, NY, USA, 2009.

4. Treuhaft, R.N.; Madsen, S.N.; Moghaddam, M.; van Zyl, J.J. Vegetation characteristics and underlying topography from interferometric data. Radio Sci. 1996, 31, 1449-1495. [CrossRef]

5. Treuhaft, R.N.; Siqueira, P.R. Vertical structure of vegetated land surfaces from interferometric and polarimetric data. Radio Sci. 2000, 35, 141-177. [CrossRef]

6. Cloude, S.R.; Papathanassiou, K.P. Polarimetric SAR Interferometry. IEEE Trans. Geosci. Remote Sens. 1998, 36, 1551-1565. [CrossRef]

7. Papathanassiou, K.P.; Cloude, S.R. Single-baseline polarimetric SAR interferometry. IEEE Trans. Geosci. Remote Sens. 2001, 39, 2352-2363. [CrossRef]

8. Cloude, S.R.; Papathanassiou, K.P. Three-stage inversion process for polarimetric SAR interferometry. IEE Proc. Radar Sonar Navig. 2003, 150, 125-134. [CrossRef]

9. Praks, J.; Kugler, F.; Papathanassiou, K.P.; Hawsek, I.; Hallikainen, M. Height estimation of boreal forest: Interferometric model-based inversion at L- and X-band versus HUTSCAT profiling scatterometer. IEEE Geosci. Remote Sens. Lett. 2007, 4, 466-470. [CrossRef]

10. Garestier, F.; Dubois-Fernandez, P.C.; Champion, I. Forest Height Inversion Using High-Resolution P-Band Pol-InSAR Data. IEEE Trans. Geosci. Remote Sens. 2008, 46, 3544-3559. [CrossRef]

11. Garestier, F.; Dubois-Fernandez, P.C.; Papathanassiou, K.P. Pine forest height inversion using single-pass X-band PolInSAR data. IEEE Trans. Geosci. Remote Sens. 2008, 46, 59-68. [CrossRef]

12. Hajnsek, I.; Kugler, F.; Lee, S.K.; Papathanassiou, K.P. Tropical-Forest-Parameter Estimation by Means of Pol-InSAR: The INDREX-II Campaign. IEEE Trans. Geosci. Remote Sens. 2009, 47, 481-493. [CrossRef]

13. Neumann, M.; Ferro-Famil, L.; Reigber, A. Estimation of forest structure, ground, and canopy layer characteristics from multibaseline polarimetric interferometric SAR data. IEEE Trans. Geosci. Remote Sens. 2010, 48, 1086-1104. [CrossRef] 
14. Garestier, F.; Dubois-Fernandez, P.; Champion, I.; Le Toan, T. Pine forest investigation using high resolution P-band Pol-InSAR data. Remote Sens. Environ. 2011, 115, 2897-2905. [CrossRef]

15. Li, Z.; Guo, M.; Wang, Z.Q.; Zhao, L.F. Forest-height inversion using repeat-pass spaceborne polInSAR data. Sci. China Earth Sci. 2014, 57, 1314-1324. [CrossRef]

16. Kugler, F.; Schulze, D.; Hajnsek, I.; Pretzsch, H.; Papathanassiou, K.P. TanDEM-X Pol-InSAR Performance for Forest Height Estimation. IEEE Trans. Geosci. Remote Sens. 2014, 52, 6404-6422. [CrossRef]

17. Xie, Q.; Zhu, J.; Wang, C.; Fu, H. Boreal forest height inversion using E-SAR PolInSAR data based coherence optimization methods and three-stage algorithm. In Proceedings of the 3th International Workshop on Earth Observation and Remote Sensing Applications, Changsha, China, 11-14 June 2014; pp. 145-150.

18. Fu, H.; Wang, C.; Zhu, J.; Xie, Q.; Zhao, R. Inversion of vegetation height from PolInSAR using complex least squares adjustment method. Sci. China Earth Sci. 2015, 58, 1018-1031. [CrossRef]

19. Fu, H.; Wang, C.; Zhu, J.; Xie, Q.; Zhang, B. Estimation of Pine Forest Height and Underlying DEM Using Multi-Baseline P-Band PolInSAR Data. Remote Sens. 2016, 8, 820. [CrossRef]

20. Wang, C.; Wang, L.; Fu, H.; Xie, Q.; Zhu, J. The Impact of Forest Density on Forest Height Inversion Modeling from Polarimetric InSAR Data. Remote Sens. 2016, 8, 291. [CrossRef]

21. Garestier, F.; Le Toan, T. Forest modeling for height inversion using single-baseline InSAR/Pol-InSAR data. IEEE Trans. Geosci. Remote Sens. 2010, 48, 1528-1539. [CrossRef]

22. Lavalle, M.; Simard, M.; Hensley, S. A temporal decorrelation model for polarimetric radar interferometers. IEEE Trans. Geosci. Remote Sens. 2012, 50, 2880-2888. [CrossRef]

23. Lei, Y.; Siqueira, P.; Treuhaft, R. A physical scattering model of repeat-pass InSAR correlation for vegetation. Waves Random Complex Media 2017, 27, 129-152. [CrossRef]

24. Lu, H.; Suo, Z.; Guo, R.; Bao, Z. S-RVoG model for forest parameters inversion over underlying topography. Electron. Lett. 2013, 49, 618-620. [CrossRef]

25. Kugler, F.; Lee, S.K.; Hajnsek, I.; Papathanassiou, K.P. Forest Height Estimation by Means of Pol-InSAR Data Inversion: The Role of the Vertical Wavenumber. IEEE Trans. Geosci. Remote Sens. 2015, 53, 5294-5311. [CrossRef]

26. Xie, Q.; Zhu, J.; Wang, C.; Fu, H. Forest height inversion by combining S-RVOG model with terrain factor and PD coherence optimization. Acta Geod. Cartogr. Sin. 2015, 6, 686-693.

27. Xie, Q.; Wang, C.; Zhu, J.; Fu, H.; Wang, C. Improvement of forest height retrieval by integration of dualbaseline PolInSAR data and external DEM data. In Proceedings of the 2015 International Workshop on Image and Data Fusion (IWIDF 2015), Kona, HI, USA, 21-23 July 2015; pp. 185-189.

28. Cloude, S.R. Robust parameter estimation using dual baseline polarimetric SAR interferometry. In Proceedings of the IEEE International Geoscience and Remote Sensing Symposium (IGARSS2002), Toronto, ON, Canada, 24-28 June 2002; pp. 838-840.

29. Lavalle, M.; Khun, K. Three-baseline InSAR estimation of forest height. IEEE Geosci. Remote Sens. Lett. 2014, 11, 1737-1741. [CrossRef]

30. Kugler, F.; Lee, S.; Papathanassiou, K.P. Estimation of forest vertical structure parameter by means of multi-baseline Pol-InSAR. In Proceedings of the IEEE International Geoscience and Remote Sensing Symposium, Cape Town, South Africa, 12-17 July 2009; pp. III-721-III-724.

31. Lee, S.K.; Kugler, F.; Papathanassiou, K.P.; Hajnsek, I. Multibaseline polarimetric SAR interferometry forest height inversion approaches. In Proceedings of the 5th International Workshop on Science and Applications of SAR Polarmetry and Polarimetric interferometry (POLINSAR2011), Frascati, Italy, 24-28 January 2011; pp. 1-7.

32. Bamler, R.; Hartl, P. Synthetic aperture radar interferometry. Inverse Probl. 1998, 14, R1-R54. [CrossRef]

33. Freeman, A.; Durden, S.L. A three-component scattering model for polarimetric SAR data. IEEE Trans. Geosci. Remote Sens. 1998, 36, 963-973. [CrossRef]

34. Xie, Q.; Ballester-Berman, J.D.; Lopez-Sanchez, J.M.; Zhu, J.; Wang, C. Quantitative analysis of polarimetric model-based decomposition methods. Remote Sens. 2016, 8, 977. [CrossRef]

35. Xie, Q.; Ballester-Berman, J.D.; Lopez-Sanchez, J.M.; Zhu, J.; Wang, C. On the use of generalized volume scattering models for the improvement of general polarimetric model-based decomposition. Remote Sens. 2017, 9, 117. [CrossRef]

36. Ballester-Berman, J.D.; Lopez-Sanchez, J.M. Applying the Freeman-Durden Decomposition Concept to Polarimetric SAR Interferometry. IEEE Trans. Geosci. Remote Sens. 2010, 48, 466-479. [CrossRef] 
37. Fu, H.; Zhu, J.; Wang, C.; Wang, H.; Zhao, R. Underlying Topography Estimation over Forest Areas Using High-Resolution P-Band Single-Baseline PolInSAR Data. Remote Sens. 2017, 9, 363. [CrossRef]

38. Zhu, J.; Xie, Q.; Zuo, T.; Wang, C.; Xie, J. Criterion of complex least squares adjustment and its application in tree height inversion with PolInSAR data. Acta Geod. Cartogr. Sin. 2014, 43, 45-51.

39. Fu, H.; Zhu, J.; Wang, C.; Xie, Q.; Zhao, R. Polarimetric SAR interferometry vegetation height inversion method of complex least squares adjustment. Acta Geod. Cartogr. Sin. 2014, 43, 1061-1607.

40. Fu, W.; Guo, H.; Li, X.; Tian, B.; Sun, Z. Extended three-Stage polarimetric SAR interferometry algorithm by dual-polarization Data. IEEE Trans. Geosci. Remote Sens. 2016, 54, 2792-2802.

41. Tabb, M.; Orrey, J.; Flynn, T.; Carande, R. Phase diversity: A decomposition for vegetation parameter estimation using polarimetric SAR interferometry. In Proceedings of the 4th European Synthetic Aperture Radar Conference (EUSAR2002), Cologne, Germany, 4-6 June 2002; pp. 721-724.

42. Lavalle, M.; Solimini, D.; Pottier, E.; Desnos, Y.-L. Forest parameters inversion using Polarimetric and Interferometric SAR data. In Proceedings of the IEEE International Geoscience and Remote Sensing Symposium, Cape Town, South Africa, 12-17 July 2009; pp. IV-29-IV-132.

43. Roueff, A.; Arnaubec, A.; Dubois-Fernandez, P.C.; Réfrégier, P. Cramer-Rao lower bound analysis of vegetation height estimation with random volume over ground model and polarimetric SAR interferometry. IEEE Geosci. Remote Sens. Lett. 2011, 8, 1115-1119. [CrossRef]

44. DLR Microwaves and Radar Institute; Swedish Defense Research Agency; Politecnico di Milano POLIMI. BIOSAR 2008: Data Acquisition and Processing Report. 2008. Available online: https:// earth.esa.int/c/ document_library /get_file?folderId=21020\&name=DLFE-903.pdf (accessed on 1 July 2017).

45. Garestier, F; Le Toan, T. Estimation of the backscatter vertical profile of a pine forest using single baseline P-band (Pol-)InSAR data. IEEE Trans. Geosci. Remote Sens. 2010, 48, 3340-3348. [CrossRef]

46. Flynn, T.; Tabb, M.; Carande, R. Coherence region shape estimation for vegetation parameter estimation in POLINSAR. In Proceedings of the IEEE International Geoscience and Remote Sensing Symposium, Toronto, ON, Canada, 24-28 June 2002; pp. 2596-2598.

47. Ferro-Famil, L.; Neumann, M.; Huang, Y. Multi-baseline POL-InSAR statistical techniques for the characterization of distributed media. In Proceedings of the IEEE International Geoscience and Remote Sensing Symposium, Cape Town, South Africa, 12-17 July 2009; pp. III-971-III-974.

48. Ballester-Berman, J.D.; Lopez-Sanchez, J.M.; Fortuny-Guasch, J. Retrieval of biophysical parameters of agricultural crops using polarimetric SAR interferometry. IEEE Trans. Geosci. Remote Sens. 2005, 43, 683-694. [CrossRef]

49. Lopez-Sanchez, J.M.; Ballester-Berman, J.D.; Marquez-Moreno, Y. Model limitations and parameterestimation methods for agricultural applications of polarimetrie SAR interferometry. IEEE Trans. Geosci. Remote Sens. 2007, 45, 3481-3493. [CrossRef]

(c) 2017 by the authors. Licensee MDPI, Basel, Switzerland. This article is an open access article distributed under the terms and conditions of the Creative Commons Attribution (CC BY) license (http://creativecommons.org/licenses/by/4.0/). 